\title{
Qualidade de projeto e percepção do parque linear Córrego do Óleo em Uberlândia-MG ${ }^{1}$
}

\section{Quality of project and perception on Linear park Córrego do Óleo in Uberlândia-MG}

\author{
Godoy, Larissa Riza Carvalho' \\ ' Universidade Federal de Uberlândia, Rua Sebastião Rangel 901, Brasil, \\ larissarcg@gmail.com
}

\begin{abstract}
RESUMO
Diante de um cenário indagado por questões visuais e perceptivas surgem necessidades de analisar temas e objetos de forma sistêmica e alternativa. O artigo propõe, com o olhar pautado em questões da qualidade do espaço construído de parques lineares, a elaboração de um método de análise da qualidade de projeto e da percepção dos usuários desses projetos após a implantação dos parques. Ghel enfatiza que a qualidade dos espaços construídos ao nível dos olhos, ou seja, na escala humana, pode ser decisiva na interpretação da qualidade de vida dos usuários e é através disso que consiste na discussão. Além de Gehl, outros autores embasaram o estudo apresentado, inclusive alguns que estabelecem reflexões sobre o ensino paisagismo, que servirão de base para a elaboração do método apresentado. O estudo consiste em elencar parâmetros que sejam significativos para o estudo do paisagismo, com foco no sistema de espaços livres da cidade.
\end{abstract}

Palavras-chave: Qualidade do espaço construído; parques lineares; percepção dos usuários; qualidade de projeto de parques lineares.

\begin{abstract}
Faced with a scenario investigated by visual and perceptual questions, the need arises to analyze themes and objects in a systemic and alternative way. The article proposes, with a view based on issues of the quality of the space constructed of linear parks, the elaboration of a method of analysis of the quality of the project and the perception of the users of these projects after the implementation of the parks. Ghel emphasizes that the quality of the spaces constructed at the level of the eyes, that is, in the human scale, can be decisive in the interpretation of the quality of life of the users and it is through this that it consists in the discussion. In addition to Gehl, other authors supported the study presented, including some reflections on landscaping teaching, which will serve as a basis for the elaboration of such a method. The study consists of listing parameters that are significant for the study of landscaping, focusing on the free space system of the city.
\end{abstract}

Keywords: Project quality; linear parks; perception of users; design quality of linear parks.

\footnotetext{
${ }^{1}$ Godoy, Larissa Riza. 1. Qualidade de projeto e percepção do parque linear do Córrego do Óleo em UberlândiaMG. In: II IMPÓSIO NACIONAL DE GESTÃO E ENGENHARIA URBANA: SINGEURB, 2019, São Paulo. Anais... Porto Alegre: ANTAC, 2019.
} 


\section{INTRODUÇÃO}

Nas últimas cinco ou seis décadas a visão e a percepção se tornaram categorias importantes para analisar diversos temas e objetos em diversas áreas das ciências humanas e sociais. $\mathrm{Na}$ segunda metade do século passado alguns arquitetos voltaram sua atenção para a percepção e a sensibilidade do indivíduo, de uma forma geral, como Henri Lefebvre, Jane Jacobs e outros. Desde então tais temas tem sido pauta de reflexões que procuram sistematizar formas alternativas de conceber o espaço urbano.

É exatamente nessa esteira que Jan Gehl define o olho humano como a "escala mais importante para o planejamento urbano" (GEHL, 2010, p. 118). Gehl não descarta, no nível da menor escala, outras necessidades e sentidos, mas já em seu estudo sobre "O uso do espaço ao ar livre pelas pessoas em cidades e bairros residenciais" de Copenhague (1966), o estudioso já observava uma estruturação do sistema urbano segundo elementos sensoriais, conforme fica evidente na nota 31 do capítulo 5 de A vida na cidade: como estudar (GEHL e SVARRE, 2018, p. 166) - a indicação da inspiração nas teorias comportamentais de Robert Sommer e a própria parceria nos estudos com sua esposa que é psicóloga são boas evidências para entender o caminho que o pesquisador percorreu.

Como resultado disso, Gehl desenvolveu ao longo dos anos uma "Lista para avaliar a qualidade dos espaços públicos" (GEHL, 2018, p. 106). Essa lista foi se modificando e sendo adaptada por ele ao longo dos últimos 40 anos: sua primeira versão foi publicada somente em 2006 em New City Life, e sua versão mais recente publicada em livro está presente em Cities for People, de 2010 (GEHL e SVARRE, p. 166).

Uma vez determinado que existe essa primazia do olhar enquanto escala do planejamento urbano e, então, da qualidade dos espaços públicos, é interessante procurar entender em que termos Gehl está definindo essa "qualidade": "[...] a qualidade da moradia e do espaço ao nível dos olhos pode ser [...] decisiva para a qualidade de vida, apesar das deficiências de outras áreas de planejamento" (GEHL, 2010, p. 118).

Quer dizer que a qualidade de vida é reflexo da qualidade da moradia e do espaço. Em todas as versões e publicações em que Gehl se debruça sobre o assunto, a ênfase recai nos aspectos funcionais e práticos oferecidos pelos espaços urbanos. Basta notar que, de seus doze critérios, os primordiais são de seguridade: proteção contra tráfego e acidentes; contra crimes e violência; contra climas desagradáveis; contra experiências sensoriais desagradáveis. Esse último, vale ressaltar, somente apresenta um aspecto visual, que seria desenvolvimento de cegueira. Assim, no rol de elementos funcionais não consta qualquer desconforto visual estético. Dos aspectos práticos, os que apontam mais detalhadamente as capacidades sensoriais a serem exploradas, remetem à "Possibilidade de ver" literal e estritamente. É somente no último critério, "Desfrutar experiências sensoriais positivas" que coube o item "qualidades estéticas". Fica assim claro de que visão Gehl está falando, e de que modo também a visão como escala funciona para o estudioso. O aspecto estético é fator de qualidade, mas é necessário que antes os aspectos funcionais e práticos do espaço tenham sido bem estruturados (GEHL e SVARRE, 2018, p. 106-107).

A proposta de Gehl se desenvolve assim a partir de elementos bem organizados e estruturados. É certo que, segundo o próprio nome dessa proposta, "Lista [de critérios] para avaliar a qualidade dos Espaços Públicos" (GEHL E SVARRE, 2018, p. 106, grifo nosso), a qual ele chamou de ferramenta em Cidades para pessoas - ele, na verdade, insere a lista dos critérios na seção "Caixa de Ferramentas" do livro (GEHL, 2010, p. 238) - a intenção é estabelecer parâmetros universais.

Mais recentemente, entretanto, uma leva de estudos interdisciplinares tem posto em evidência o sistema cognitivo-participativo dos indivíduos, de modo que se altera, ao menos em teoria, o lugar do indivíduo em relação à escala espacial. Nos estudos sobre arquitetura, Florencio Zoido Naranjo apontou a relação entre a ordenação do espaço público e sua função democrática através da participação cidadã (NARANJO, 2002). Embora Naranjo recorra à diversos conceitos políticos e sociológicos, o autor demonstra mais claramente que esse sistema cognitivo-participativo reflete um elemento perceptivo: a 
construção de um aparato social e cultural responsável por ajudar a conceber os espaços urbanos (NARANJO, 2002).

De maneira semelhante, já no fim dos anos 1960, Kevin Lynch apontava a construção e ordenação dos espaços como resultantes da percepção e da atuação dos sujeitos na cidade (LYNCH, 1960).

Pensar todos esses elementos pode ser necessário para compreender o espaço urbano na contemporaneidade, especialmente os espaços urbanos da contemporaneidade. É nesse aspecto que devem ser concebidos os parques lineares: espaços urbanos contemporâneos. Eugênio de Queiroga aponta que "a maioria dos projetos [de parques] concebidos na primeira década do século XXI já se mostra efetivamente mais sensível ao papel ambiental [...] indo além dos programas convencionais ligados ao lazer e à prática de atividades físicas" (QUEIROGA, 2012, p. 99). E ainda mais que a sensibilidade ao papel ambiental, os planejamentos de parques contemporâneos têm aceitado também um papel social e histórico que levam à contribuição para construção de referências e identidade dos seus usuários.

É conveniente, nessa altura, apontar que a pesquisa da qual este texto resulta, procura justamente entender a qualidade do espaço construído de parques lineares e a percepção de seus respectivos usuários. Ou seja, incide sobre a proposta de Gehl, mas também visa entender a dimensão da percepção conforme sugerida por Lynch e Naranjo. Além disso, deve também compreender seu objeto, o parque, enquanto um produto de um momento histórico e social específico, conforme Queiroga esclareceu. Dessa maneira, o objetivo desse texto é justamente explorar estas questões de modo que elas possam ajudar a elaborar uma forma sistemática de estudar a qualidade do espaço construído de parques e a percepção dos indivíduos em relação a esse espaço construído em específico.

\section{OBJETO DE ESTUDO}

\subsection{Parque Linear Córrego do Óleo}

O Parque Linear do Córrego do Óleo, localizado entre os bairros Luizote de Freitas e Chácaras Tubalina, possui $220.000 \mathrm{~m}^{2}$ de área total. Possui calçadão de aproximadamente $4 \mathrm{~km}$ de extensão e aparelhos de ginástica. Possui quadra poliesportiva, arquibancada, ciclovia e parque infantil. Será objeto de estudo da pesquisa e surgiu com a finalidade de conservar áreas de preservação permanente das cidades, contribuindo com o equilíbrio ambiental e integrando os rios e suas margens com o tecido urbano - como é a proposta dos parques lineares em geral. Uberlândia é um município brasileiro do estado de Minas Gerais, na região Sudeste do país. A cidade localiza-se no Triângulo Mineiro.

\section{METODOLOGIA}

O estudo foi elaborado a partir de parâmetros que foram elencados por uma revisão de estudos. A base da revisão foram conceitos que serviram como referência para o estudo da paisagem. Através dos parâmetros elencados se propõe uma metodologia de compreensão do espaço construído dos parques lineares.

É pertinente deixar claro que alguns dos estudos que serviram de referência (como Feghali e Tardin) se baseiam em uma transposição da análise da paisagem até a etapa de projeto, afinal se tratam de metodologias pedagógicas do ensino de paisagismo. Difere da problematização tratada no artigo, visto que este se enquadra em analisar o espaço construído, o projeto paisagístico e arquitetônico de parques lineares implantados. E tem como objetivo, através dos parâmetros elencados, fomentar a discussão acerca dos modelos que estão sendo produzidos atualmente, ou seja, uma análise pós-ocupação.

Mesmo com essa diferença, a inspiração advinda de metodologias pedagógicas se tornou um instrumento válido na abordagem. Segundo Feghali, esses conceitos possibilitam a integração em diferentes dimensões de análise do espaço: morfológico, comportamental e 
sensorial e são relevantes para a apreensão dos espaços livres públicos pois permitem uma análise não só interpretativa, mas também valorativa dos contextos de intervenção (FEGHALI, 2007, pp. 11). Ou seja, além de elementos físicos, os parâmetros escolhidos consideram elementos de valores na elaboração de uma crítica da paisagem do espaço construído.

Os parâmetros escolhidos foram elencados diante uma seleção de alguns autores. Segundo Aguiar, Kevin Lynch contribuiu na tentativa dos elementos da urbanidade. Lynch propõe e exercita um "modo prazeroso" de olhar a cidade como um conjunto de sequências espaciais onde, nas palavras do autor, "os elementos móveis de uma cidade e, em especial, as pessoas e suas atividades, são tão importantes quanto as partes físicas estacionárias" (AGUIAR, 2006, pp.66). De sua estrutura de análise foram selecionados dois conceitos que embasaram dois parâmetros de análise, são eles: vias e limites.

Um conceito muito importante se trata de uma busca por definições que identifiquem características mais genuínas dos elementos físicos que compõem os espaços e que podem ser percebidos como parte da identidade visual da área (TARDIN, 2008, pp. 148-157). Ela define, então, como atributos perceptivos em seu estudo, são eles: elementos cênicos, áreas de emergência visual, fundos cênicos e marcos históricos. Vale ressaltar que todos esses parâmetros no momento da eleição possuem um alto grau de subjetividade e está sujeita a distintas considerações sobre seu valor.

Para Feghali (2007, pp.12) a criação dos conceitos como metodologia pedagógica possibilita a valorização dos aspectos de uma situação a ser analisada. E os parâmetros que serão utilizados como referência são: significação, continuidade e viscosidade.

Para Ghel a lista de critérios de qualidade foi desenvolvida com base em conhecimentos fundamentais sobre sentidos e necessidades humanas e sobre o que faz as pessoas se sentirem confortáveis e permanecerem no espaço público (GEHL e SVARRE, p. 106). Os parâmetros, então, considerados nessa análise foram: proteção contra o tráfego, segurança, proteção contra crimes e violência, experiências sensoriais, espaços para caminhar, espaços de permanência, ter onde se sentar, possibilidade de observar, oportunidade de conversar, locais para se exercitar, escala humana, possibilidade de aproveitar o clima e boa experiência sensorial.

E também a vitalidade, muito analisada por Ghel, então definida como um espaço convidativo. Caracteriza os espaços como vivos quando transpassam sinais amistosos e acolhedores que promovem integração social. Esclarece este conceito como relativo sendo que a vitalidade nas cidades não se limita à quantidade de pessoas e sim a sensação que o espaço transmite, se ela convida ou afasta as pessoas, se as atividades sociais e de lazer estão combinadas ou fragmentadas. (GHEL, 2013, pp.75).

\section{CONCLUSÕES}

A partir da elaboração dos parâmetros de qualidade do espaço construído, é possível compreender uma estrutura de avaliação da percepção dos usuários sobre os parques lineares. Assim, a aplicação de tais parâmetros no contexto de parques analisados, através dessas visões permitirão uma comparação qualitativa que evidencie os usos e as apropriações dos espaços livres e parques lineares.

O que se apresenta enquanto resultado da pesquisa até o momento se trata de uma revisão bibliográfica que resulta na eleição dos parâmetros da análise da qualidade de projeto e percepção dos usuários, objetivando também levantar e discutir questões frente aos modelos de parques lineares que vem sendo produzidos e implantados nas cidades.

\section{REFERÊNCIAS}

CULLEN, G. Paisagem Urbana. São Paulo: Martins Fontes, 2006. 
FEGHALI, Maria Elisa; LASSANCE, Guillherme. Da análise às intenções do projeto: conceitos para o processo de concepção da paisagem. In: Paisagem e Ambiente, São Paulo, n. 23, p. 10-19, june 2007. ISSN 2359-5361. Disponível em:

https://www.revistas.usp.br/paam/article/view/86864. No dia 26/11/17

GEHL, J. Cidades para pessoas. São Paulo: Perspectiva, 2013.

GEHL, J. Life between buildings: using public space. Washington: Island Press, 2011.

GEHL, J.; SVARRE, B. How study public life. Washington: Island Press, 2013.

LYNCH, K. A imagem da cidade. São Paulo: MariTns Fontes, 1997.

NARANJO, Florencio Zoido. "El paisaje y su utilidade para la ordenación del territorio". In: Consejería de Obras Públicas y Trasnportes. Paysaje y ordenación del territorio. Andaluzia: Junta de Andalúcia/Consejería de Obras Públicas y Trasnportes, 2002.

QUEIROGA, Eugênio Fernandes. Dimensões públicas do espaço contemporâneo: resistências e transformações de territórios, paisagens e lugares urbanos brasileiros. São Paulo: FAUUSP, 2012. 284 F. Tese (Doutorado em Livre Docência) - Programa de Pós-Graduação em Arquitetura e Urbanismo, Faculdade de Arquitetura e Urbanismo, Universidade Federal de São Paulo, São Paulo, 2012.

REIS, Antônio Tarcísio da LUZ; LAY, Maria Cristina Dias. Avaliação da qualidade de projetos uma abordagem perceptiva e cognitiva. In: Ambiente construído. Porto Alegre, v. 6, n. 3, p. 21-34, jul./set. 2006. Disponível em: https://www.lume.ufrgs.br/handle/10183/55493. Acesso em $15 / 11 / 2018$.

SERPA, Angelo. Milton Santos e a Paisagem: Parâmetros para a Construção de uma Crítica da Paisagem Contemporânea. In: Paisagem e Ambiente, São Paulo, n. 27, p. 131-138, june 2010. ISSN 2359-5361. Disponível em: http://www.revistas.usp.br/paam/article/view/77376. Acesso em 26/11/17.

TÂNGARI, Vera; SCHLEE, Mônica; NUNES, Maria; REGO, Andrea; RHEINGANTZ, Paulo; DIAS, Maria. Sistema de espaços livres nas cidades brasileiras - um debate conceitual. In:

Paisagem Ambiente: ensaios - n. 26 - São Paulo - p. 225 - 247 - 2009.

TARDIN, R. Espaços livres: sistema e projeto territorial. Rio de Janeiro: 7 Letra, 2008. 